\title{
Beneficial effects of amino acid-functionalized graphene nanosheets incorporated in the photoanode material of dye-sensitized solar cells: A practical and theoretical study
}

\author{
Mahmood Taki ${ }^{\mathrm{a}}$, Behzad Rezaei ${ }^{1, \mathrm{a}}$, Najmeh Fani $^{\mathrm{b}}$, Sedigheh Borandeh ${ }^{\mathrm{c}}$, Amir Abdolmaleki $^{\mathrm{a}}$, Ali A. Ensafi ${ }^{\mathrm{a}}$ \\ ${ }^{a}$ Department of Chemistry, Isfahan University of Technology, Isfahan 84156-83111, IR Iran \\ ${ }^{b}$ Department of Chemistry, University of Isfahan, Isfahan 81746-73441, IR Iran \\ ${ }^{c}$ Center for Nanotechnology in Drug Delivery, Shiraz University of Medical Science, Shiraz 71345, IR Iran
}

\begin{abstract}
In this research, covalently functionalized graphene oxide (GO) with some biocompatible amino acids were incorporated to the $\mathrm{TiO}_{2}$ film and employed as the photoanodes of dye-sensitized solar cells (DSSCs). Electrochemical analysis of the amino acids-functionalized graphene oxide (AFGs) confirmed that the attached amino acids could be acted as a reducing agent of the GO. The photovoltaic performance of the assembled DSSCs under illumination of simulated AM 1.5 sunlight $\left(100 \mathrm{~mW} \mathrm{~cm}{ }^{-2}\right)$ showed an enhancement of about 4.1 and 1.8 fold for the solar cell assembled with the tyrosine-functionalized GO in relation to the control solar cells constructed with $\mathrm{GO}-\mathrm{TiO}_{2}$ composite and blank $\mathrm{TiO}_{2}$ film, respectively. These results were in accordance with electron life time and transport time resulted from the open circuit voltage decay (OCVD), electrochemical impedance spectroscopy (EIS) and intensity modulated photocurrent spectroscopy (IMPS) analysis. The density functional theory (DFT) calculations exhibited a proper spacial arrangement for the tyrosine-GO structure that could improve electron transfer between the adjucent GO sheets. Density of electronic states (DOS) exhibited a gap between the highest occupied molecular orbital (HOMO) and the lowest unoccupied molecular orbital (LUMO) energy levels for the simulated AFG structures. This effect could facilitate the light adsorption process in near-IR region.
\end{abstract}

Keywords: Dye-sensitized solar cells, Functionalized graphene, Band gap opening, Density of electronic states

\footnotetext{
${ }^{1}$ Corresponding Author. Tel.: +983133913268; fax: +98 3133912350.

E-mail address: rezaei@cc.iut.ac.ir, rezaeimeister@gmail.com.
} 


\section{Introduction}

Dye-sensitized solar cells are third generation of the photovoltaic devices that has been attracted much interest due to the ease of fabrication and high energy conversion efficiency. A wide band gap oxide semiconductor sensitized with light absorbing molecules was coated on a transparent conductive substrate and generate photoelectrons. The electrons are transferred from the external load and coming back to the cell via cathode to reduce the oxidized dye by means of a redox mediator [1]. The DSSC efficiency is limited by the loss mechanisms in which the injected electrons are captured by oxidized dye or redox electrolyte [2]. There are numerous literatures reporting an enhanced photovoltaic performance of the DSSC by inhibiting the electron recombination rate. Deposition a blocking layer in the beneath of the semiconductor film [3], developing core-shell structures [4] and conductivity enhancement additives between the semiconductor particles [5] are the most important efforts to overcome the loss mechanisms in the DSSC. Carbon nanostructures are one of the promising new materials showing significant improvement in the solar cells [6]. The graphene or its functional compounds were used in almost all parts of the DSSC to get an enhanced properties [7-9]. Graphene is a monoatomic layer of the graphite with extraordinary and superior electronic, thermal and mechanical properties. The $\mathrm{sp}^{2}$ hybridized carbon atoms in the honeycomb configuration provide high electrical and thermal conductivity which offers great number of applications in various research fields such as batteries and fuel cells, supercapacitors, photovoltaic, water splitting and hydrogen storage devices [10,11]. Thanks to the rich chemistry of graphene, other desired properties could be attained by modification of graphene structure with covalently or non-covalently attached functional groups. Synthesis of new materials, improving biocompatibility, addition of chromophores and band gap opening are some applications of the functionalized graphene sheets $[12,13]$.

Graphene oxide (GO) is usually a suitable precursor for the synthesis of new graphene derivatives due to the potentially active functional groups emerged on the graphene sheet after oxidation. 
Hydroxyl, carbonyl, epoxy and carboxyl functional groups are existed on the GO sheets that could be attached to other molecules or radicals $[14,15]$.

The interaction of amino acids with the graphene and GO was studied by several authors. In these works, a green procedures were developed for the reduction of GO with amino acids [16,17] and non-covalent adsorption of amino acids on the GO sheets were studied by theoretical methods [18-20].

In this research for the first time, covalently functionalized amino acid graphene nanosheets were incorporated to the $\mathrm{TiO}_{2}$ nanoparticles film to improve electron transport and photovoltaic properties of the photoanode in the DSSC. The AFGs were successfully synthesized and characterized in the previous work [21]. An efficient electrophoretic deposition (EPD) under AC signal [22] was employed to deposit a highly uniform and dense film of the $\mathrm{TiO}_{2}$ composite on the transparent conductive substrates.

\section{Material and methods}

2.1. Materials and reagents $\mathrm{Semiconductor}$ used in this study was commercially available $\mathrm{TiO}_{2}$ (P25, Degussa, Germany) composed of anatase (85\%) and rutile (15\%) crystal modifications as determined by X-ray diffraction analysis. $\mathrm{TiO}_{2}$ suspensions suitable for the EPD were prepared with a mixture of $80: 20 \% \mathrm{v} / \mathrm{v}$ of high purity 2-propanol and ethanol as the solvent. Magnesium nitrate $\left(99.99 \%\right.$ Merck) with the concentration of $1.0 \times 10^{-4} \mathrm{~mol} \mathrm{~L}^{-1}$ was added as the electrolyte to impose positive charge on $\mathrm{TiO}_{2}$ surface. The N719 dye, ditetrabutylammoniumcis-bis (isothiocyanato) bis (2, 2'-bipyridyl-4, 4, dicarboxylato) ruthenium (II), was used as the standard sensitizer. The electrolyte used for the solar cell fabrication was composed of $0.85 \mathrm{~mol} \mathrm{~L}^{-1}$ methylhexylimidazolium iodide, $0.05 \mathrm{~mol} \mathrm{~L}^{-1}$ iodine, $0.1 \mathrm{~mol} \mathrm{~L} \mathrm{~L}^{-1} \mathrm{LiI}$ and $0.2 \mathrm{~mol} \mathrm{~L}^{-1}$ 4-tertbutylpyridine in acetonitrile. All solvents were of analytical grade and were purchased from the commercial sources. Fluorine-doped tin oxide (FTO, $15 \Omega$ square $^{-1}$, Solaronix) was used as the conductive substrate of $\mathrm{TiO}_{2}$ films. 
2.2. Instrumentation A signal generator (GW Instek GFG-2080H) coupled with a signal amplifier was used for producing AC electrical fields for the particle deposition. The applied signals was confirmed with a digital oscilloscope (GW Instek GDS-1052U) connected to the EPD cell. Morphologies of the deposited films were observed with the scanning electron microscopy (SEM, Philips-XL30). The absorption spectra of the dye-loaded photoanodes were recorded with Avantes Avaspec 2048 spectrophotometer with halogen and deuterium lamps. Eco-Chemie Autolab PGSTAT 302N electrochemical workstation controlled with NOVA software was used for all electrochemical studies. Photovoltaic performance of the assembled solar cells illuminated with AM 1.5 simulated sunlight $\left(100 \mathrm{~mW} \mathrm{~cm}^{-2}\right)$ were determined by Biologic SP-300 potentiostat. A blue light LED $(455 \mathrm{~nm})$ driven with a sinusoidal wave in the frequency range of 0.01 to $20 \mathrm{~Hz}$ superimposed on a DC signal was employed for the IMPS study. The intensity of the AC part of the generated beam was adjusted to about $10 \%$ of the DC light which was measured with a standard Si-based solar cell.

2.3. Electrochemical tests Working electrode in all electrochemical tests was AFG-immobilized on a glassy carbon (GC) electrode. $\mathrm{Ag} / \mathrm{AgCl}$ and a $\mathrm{Pt}$ wire were used as the reference and counter electrodes, respectively. Cyclic voltammetry $(\mathrm{CV})$ and EIS analysis performed in $3.0 \times 10^{-3} \mathrm{~mol} \mathrm{~L}^{-1}$ of $\mathrm{Fe}^{2+} / \mathrm{Fe}^{3+}$ aqueous solution. The supporting electrolyte was $0.1 \mathrm{~mol} \mathrm{~L}{ }^{-1}$ of pure $\mathrm{KNO}_{3}$. The EIS spectra were recorded in $0.2 \mathrm{~V}$ vs. $\mathrm{Ag} / \mathrm{AgCl}$ with potential amplitude of $0.01 \mathrm{~V}$ and the scanned frequency between $0.1 \mathrm{~Hz}$ to $100 \mathrm{kHz}$. Electrochemical reduction of AFGs was performed in the phosphate buffer with $\mathrm{pH}$ of 11 . The dielectric properties of the $\mathrm{AFG}-\mathrm{TiO}_{2}$ photo-electrodes were investigated using potentiodynamic EIS studies. The working electrode was the deposited composite films on FTO substrate and the $\mathrm{Ag} / \mathrm{AgCl}$ and a $\mathrm{Pt}$ wire were used as the reference and counter electrodes, respectively. The electrolyte was aqueous solution of $\mathrm{KCl}(3 \mathrm{M})$ and the impedance data were recorded in dark with the polarization frequency of $10 \mathrm{kHz}$. 
2.4. EPD procedure AFGs were dispersed in pure water with the concentration of $1.0 \mathrm{~g} \mathrm{~L}^{-1}$ and sonicated for $5 \mathrm{~h}$ at room temperature to make stable suspensions. To impart negative charge on the dispersed AFG particles, the pH of all AFG suspensions were adjusted in the range of 7.5-8.5. Subsequently, the AFG suspensions were introduced to the $\mathrm{TiO}_{2}$ suspension and the formed composite was sonicated for $3 \mathrm{~h}$. The concentrations of the $\mathrm{TiO}_{2}$ and $\mathrm{AFGs}$ in the composite suspensions were $2 \mathrm{~g} \mathrm{~L}^{-1}$ and $5 \mathrm{mg} \mathrm{L}^{-1}$, respectively. FTO substrates were cleaned with detergent, deionized water, ethanol and acetone. In the EPD cell, an FTO was used as the deposition substrate (cathode) and a stainless steel plate were used as the counter electrode (anode). The distance between both electrodes was maintained at $1.0 \mathrm{~cm}$. The AC signal applied to the EPD cell was sinusoidal wave with frequency of $1.0 \mathrm{kHz}$ and amplitude of $9.0 \mathrm{~V}$ coupled with $4.5 \mathrm{~V}$ DC signal [22]. The deposition time was 15 min for preparing all of the composite films.

2.5. Fabrication of DSSCs The deposited films were dried at $120{ }^{\circ} \mathrm{C}$ for $2 \mathrm{~h}$ in the atmosphere and placed in $5.0 \times 10^{-4} \mathrm{~mol} \mathrm{~L}{ }^{-1}$ of the N719 dye solution and maintained under dark for $12 \mathrm{~h}$. The solar cells were assembled with Pt-coated FTOs as the cathode and sealed using a thermoplastic frame. The iodine based electrolyte was injected via predrilled hole on the cathode that was sealed afterward.

2.6. Theoretical investigation Geometrical structures of the AFGs were optimized without any symmetry restrictions using DFT calculations with the Lee-Yang-Parr correlation functional (B3LYP) under 6-311G (d) basis set. ORCA 3.0.3 electronic structure package [23] was used for the energy minimization process with the input files prepared with Gabedit 2.4.7 [24]. VMD 1.9.2 molecular visualization package and Multiwfn 3.3.8 wavefunction analysis program [25] were used to investigate the optimized structures and obtaining DOS diagrams, respectively. All calculations were performed on a PC equipped with a $3.4 \mathrm{GHz}$ Intel Core (TM) i7 CPU running Linux operating system. 


\section{Results and discussion}

In the previous study, 7 natural aromatic (phenylalanine and tyrosine) and aliphatic (alanine, isoleucine, leucine, methionine and valine) amino acids were covalently bound to the epoxy and carboxyl groups on the GO to make environmental friendly graphene derivatives. Different aspects of the functionalized amino acid were consisted of partial reduction of GO to graphene, increase GO layers distance and develop new interaction between GO sheets [21].

3.1. Electrochemical properties of AFGs The most significant properties of the graphene based structures that play important role in the electrochemical applications are good electrical conductivity and electrocatalytic activity. These features leading to the reduce charge transfer resistance in the electrochemical systems that was mentioned earlier. However, the GO is electrochemically inert due to the $\mathrm{sp}^{3}$-bonded carbon atoms [26]. In the synthesis route of the AFGs, no kind of the GO reduction process was performed so, poor electrocatalytic activities of the AFGs were expected. CV and EIS analysis were used as the powerful tools to have an insight of the electrochemical catalytic activities of the AFGs. In another CV experiment, all the graphene derivatives were electrochemically reduced in aqueous buffer solution to find possibility of reduction for each of the AFGs. Fig. 1 shows the CVs, complex plane plots and the reduction peaks of the AFGs immobilized on GC electrode. The complete list of the recorded anodic peak currents $\left(i_{\mathrm{pa}}\right)$, charge transfer resistance on the working electrode $\left(R_{\mathrm{ct}}\right)$ and the reduction currents of AFGs $\left(i_{\text {red }}\right)$ in the electrochemical experiments are illustrated in Table 1.

(Fig.1 is here.)

(Table 1 is here.)

The anodic and cathodic peak currents of the recorded CVs in the Fe (II) solution significantly decreased with the presence of the GO. However, an enhanced anodic current observed for all of the AFGs in comparison to the bare and GO-immobilized GC electrodes. The $i_{\mathrm{pa}}$ is typically increased with the higher microscopic electrode surface area or greater electrocatalytic activity of 
the electrode modifier [27]. The data in Table 1 shows that except Leucine, the increase in $i_{\mathrm{pa}}$ is accompanied by a decline in the $R_{\mathrm{ct}}$ that confirms the electrocatalytic activities of the synthesized AFGs. This effect possibility related to the reduction of GO in the presence of amino acids which was mentioned earlier [16,17] or formation of special AFG structures [21] with improved charge transfer capabilities. The GO is reduced to the graphene at the negative potentials in the range of -1.2 to $-1.5 \mathrm{~V}$ vs. $\mathrm{Ag} / \mathrm{AgCl}[28]$. So, the cathodic peaks in this region could be regarded as the reduction of GO functional groups. The reduced nature of AFGs was verified with the cathodic current recorded for the reduction of the AFGs which were smaller than the current recorded for the GO in Table 1 (except GO-isoleucine).

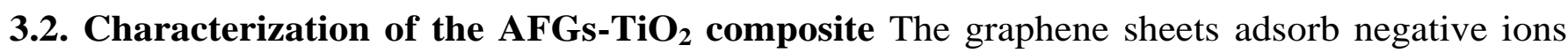
existed in polar solvents and obtain negative charge [29]. The alkaline water used to disperse the AFG nanoparticles could enhance acquiring negative surface potential. To confirm adsorption of the negative charge on the AFG particles, zeta potential of the dispersed AFGs in the prepared suspensions were measured (Table 2).

(Table 2 is here.)

All the AFGs obtained negative charge. The phenylalanine and tyrosine coordinated GO nanoparticles had the lowest surface charge due to the increased interlayer interaction governed by the aromatic rings. This interaction tends to aggregate the GO sheets in polar solvent. More discussion about this interaction will be presented in the theoretical section.

The $\mathrm{TiO}_{2}$ nanoparticles adsorb positive ions at a $\mathrm{pH}$ lower than 5.5 (point of zero charge) making positively charged particles [30] which is electrostatically adsorbed on the negatively charged AFGs sheets. The resulted $\mathrm{AFGs}-\mathrm{TiO}_{2}$ composite particles were collected on the cathode surface under DC electrical field showing that the overall charge on the composite particles was positive. The infrared spectra of the $\mathrm{AFGs}-\mathrm{TiO}_{2}$ were used to address detailed interaction between AFGs and $\mathrm{TiO}_{2}$ nanoparticles (Fig. 2). 
(Fig. 2 is here.)

The band at $664 \mathrm{~cm}^{-1}$ is related to the $\mathrm{Ti}-\mathrm{O}$ stretching vibration of $\mathrm{TiO}_{2}$ lattice. The absorption band at $1358 \mathrm{~cm}^{-1}$ obtained from the inherent structure of graphene sheets [31]. The relatively broad peak observed in $1635-1650 \mathrm{~cm}^{-1}$ is attributed to the $\mathrm{C}=\mathrm{O}$ stretching groups of the amide linkage in the AFGs and unbounded carboxylic acid groups existed on the GO sheets. The broad peak appeared around $3400 \mathrm{~cm}^{-1}$ is caused by the $\mathrm{O}-\mathrm{H}$ stretching bands of the hydroxyl and free carboxylic acid groups on GO sheets. Regarding the FTIR spectrums obtained from the AFGs [21], the $\mathrm{C}=\mathrm{O}$ peak is shifted to the lower frequencies when attached to the $\mathrm{TiO}_{2}$ particles. In addition, the absorption peak of the hydroxyl group becomes smaller (except GO-phenylalanine, tyrosine and methionine). Therefore, it can be concluded that the free carboxylic groups of the GO sheets were involved in the adsorption of AFGs to the $\mathrm{TiO}_{2}$ structure via ester linkage. However, it seems that the interaction between aromatic $\mathrm{AFGs}$ and $\mathrm{TiO}_{2}$ is different and could not just accompanied by the ester linkage.

The SEM images of the cross sectional area of the deposited films were used to verify incorporation of the AFGs in the semiconductor particles (Fig. 3) and Fig. 4 shows the morphology of the deposited particles which included GO functionalized with 4 amino acids.

(Fig. 3 and 4 is here.)

It can be seen from the Fig. 3, the included AFG particles were uniformly distributed in the photoanode film confirming formation of stable $\mathrm{AFGs}-\mathrm{TiO}_{2}$ composites. It was concluded from the Fig. 4 that the morphology of the deposited films were not significantly affected by the incorporated AFGs. The particle sizes of AFGs-TiO 2 composites were in the range of 50-150 nm excluding big clusters.

Fig. 5 illustrates the absorption spectra of the dye-loaded AFGs-TiO 2 photoanodes. It can be seen that with addition of the GO and its derivatives the amount of adsorbed dye was increased especially for the aromatic AFGs. This effect was also cited with other authors which was 
interpreted by higher roughness of graphene- $\mathrm{TiO}_{2}$ composite nanoparticles [32] or anchoring dye to the active functional groups of the GO sheets [12].

(Fig. 5 is here.)

3.3. Photovoltaic characteristics of the fabricated DSSCs The photovoltaic parameters consisted of open circuit voltage $\left(V_{\mathrm{OC}}\right)$, short circuit current density $\left(J_{\mathrm{SC}}\right)$, fill factor $(F F)$ and the overall cell efficiency $(\eta)$ were obtained from the $J-V$ measurement of the assembled solar cells (Fig. 6) and summarized in Table 3.

(Fig. 6 is here.)

(Table 3 is here.)

The highest solar cell efficiencies were obtained with the addition of GO functionalized with tyrosine and phenylalanine. The performance of the DSSCs having other AFGs showed an improvement over the GO and a decline related to the control solar cells with no additives. It can be concluded from the photovoltaic test results that the GO and its derivatives with aliphatic amino acids resulted a reduced cell performance. In contrast, the DSSCs fabricated with photoanodes having GO with aromatic amino acids showed better cell efficiencies. These results might not just because of higher adsorbed dye molecules on the aromatic AFGs composite photoanodes (Fig. 5) since, $\mathrm{TiO}_{2}$ photo-electrode containing valine-functionalized GO was not followed this trend. The FF obtained for the solar cell having leucine-functionalized GO was lower than other AFGs-GO that could be related to the big charge transfer resistance obtained on the GC electrode (Table 1).

The incorporated graphene derivatives changed the electron donating potential of the semiconductor layer. The potentiodynamic-EIS analysis was employed to study the capacitance of the electron-hole separation region. The Mott-Schottky equation was used to estimate the flat band potentials $\left(E_{\mathrm{fb}}\right)$ of the semiconductor layers [33]. 
$\frac{1}{C^{2}}=\frac{2}{e \varepsilon \varepsilon_{0} N}\left(E-E_{f b}-\frac{k T}{e}\right)$

where, $C$ is the capacitance of the space charge region, $\varepsilon$ is the dielectric constant of the semiconductor, $\varepsilon_{0}$ is the permittivity of the free space, $\mathrm{N}$ is donor concentrations, $E$ is the applied potential and $E_{\mathrm{fb}}$ is the flat band potential of the semiconductor. Different values of the $E_{\mathrm{fb}}$ were obtained with incorporating functionalized graphene additives to the $\mathrm{TiO}_{2}$ film. There was a good relationship between $E_{\mathrm{fb}}$ and the $V_{\mathrm{OC}}$ (Table 3), since the open circuit voltage is corresponded to the gap between the Fermi level of the semiconductor and the reduction potential of the redox electrolyte [1].

The energy conversion efficiency of the DSSCs in the visible and near-IR wavelength was studied with the IPCE analysis (Fig. 7).

(Fig. 7 is here.)

Two broad performance peaks were observed in all the IPCE graphs corresponded to the absorption spectra of the N719 dye [34]. However, a slight difference between the wavelengths of the DCCSs response could be recognized. All of the DSSCs with aliphatic AFGs exhibited similar IPCE graphs (except isoleucine) that were also comparable to the DCCS with no additive. A better light harvesting in the near-IR region was exhibited with the solar cells having phenylalanine-GO which was clearly showed higher energy conversion efficiency in the longer wavelengths in the range of $675-750 \mathrm{~nm}$.

\subsection{Kinetic behavior of the DSSCs}

An estimation of the electron recombination lifetime $\left(\tau_{\mathrm{n}}\right)$ in the AFG-embedded DSSCs was accomplished with the OCVD test (Fig. 8-a and b). $\tau_{\mathrm{n}}$ was calculated using the derivate of the recorded transient $V_{\mathrm{OC}}$ from the following equation ${ }^{13}$ :

$\tau_{n}=-\frac{k_{B} T}{e}\left[\frac{d V_{O C}}{d t}\right]^{-1}$

Where, $\mathrm{k}_{\mathrm{B}}$ is Boltzmann constant, $e$ is the elementary charge and $T$ is the absolute temperature. 
The transient open circuit voltage of the solar cell reflects the electron-hole recombination rate. The aromatic-functionalized GO showed the highest $V_{\mathrm{OC}}$ stability after the end of illumination that was in good agreement with the higher cell efficiency obtained from the $J-V$ measurements (Fig. 6).

(Fig. 8 is here.)

The EIS study of the illuminating DSSC is a reliable analysis to investigate the kinetics of the electron transport and recombination reactions [35-37]. Two semicircles typically observed in the Nyquist plot that was contributed to the charge transfer on the cathode at high frequency region and electron injection from the sensitizer to the semiconductor at lower frequencies. The semicircle in the high frequency might become invisible due to the high concentration of $\mathrm{Pt}$ deposited on the cathode surface [35]. The EIS data was fitted to the proper electrochemical circuit model (Fig. 8-c) and the resulted information which were consisted of electron recombination lifetime $\tau_{\mathrm{n}}=1 / 2 \pi f_{\min }$ and photo-electron injection resistance $\left(R_{\text {inj. }}\right)$ that are listed in Table 4. $f_{\min }$ is the frequency of the phase shift in the Bode plots [35].

The Highest $\tau_{\mathrm{n}}$ and the lowest $R_{\text {inj }}$ were obtained for the solar cells fabricated with the photoanodes having tyrosine and phenylalanine-functional GO. The lower $R_{\text {inj }}$ accounts for more facile electron injection to the conduction band (CB) of the semiconductor.

IMPS measurement is another precise analysis tool used for investigations of the electron diffusion kinetics under short circuit condition. The solar cell analysis in the EIS and OCVD tests were performed in open circuit voltage conditions, namely no current was passed from the illuminating cell. Therefore, all the generated photo-electrons are contributed in the recombination process. While, in the IMPS measurements, the illuminating solar cell was tested in the short circuit conditions and the injected photo-electrons were transferred from the semiconductor layer with the trap-limited diffusion mechanism [38,39]. The electron transport time in the $\mathrm{TiO}_{2}$ film $\tau_{\mathrm{d}}=1 / 2 \pi f_{\text {IMPS }}$ was summarized in Table $4 . f_{\text {IMPS }}$ is the frequency of the minimum imaginary part of the recorded current [40] which is shown in Fig. 6-d. 
(Table 4 is here.)

The smallest electron transport time was obtained for the tyrosine-functionalized GO. Other AFGs showed bigger transport times over the control solar cell with no additives. However, except phenylalanine, all the $\tau_{\mathrm{d}}$ values are higher that the electron transport time obtained for the GO. The possibility of the electron-hole recombination would be decreased with the higher electron transport time that resulted a better photovoltaic performance [32].

3.5. Theoretical studies The functional amino acids bound to the carboxylic group existed on the edges of the GO sheets to form amidic bridge. Moreover, they could be formed amine linkage with the carbon of the surface epoxy group [21]. In this study, graphene sheet containing 20 benzene rings bound to one epoxy and four carboxylic groups was used as a model of GO sheet. Two molecules of amino acids were attached to the epoxy and carboxylic groups to make a simplified model of AFGs. The geometry-optimized structures obtained in the $a b$ initio energy minimization process were illustrated in Fig. 9-a.

(Fig. 9 is here.)

The aromatic rings of tyrosine and phenylalanine exhibited interesting geometry in relation to the GO sheet. Two rings of tyrosine are aligned in parallel to the GO sheet while, one of the rings of phenylalanine attached to GO is placed perpendicular to the GO sheet (Fig. 9-b). The enhanced electrochemical and photovoltaic properties of the GO functionalized with tyrosine could be interpreted with the strong $\pi-\pi$ interactions between GO rings which are induced by the parallel aromatic rings. This effect was verified with the sheet scrolling observed with the SEM images and the layer-to-layer distance determined by the XRD in the previous paper [21]. Phenylalanine is also showed similar behavior but, the existence of the perpendicular ring weakened the interaction between adjacent GO sheets. In the AFGs with aliphatic amino acids the interlayer distance was increased due to the intercalation amino acids and all the photovoltaic improvement 
resulted in the compare to the GO are attributed to the reducing properties of the attached amino acids.

The DOS for each of the AFGs were calculated from the geometry-optimized structures (Fig. 10a) and were used to estimate the HOMO and LUMO energy levels of the AFGs that are illustrated graphically in Fig. 10-b. It is clearly observed that a gap was formed between the HOMO and LUMO energy levels with functionalizing the GO. The AFGs could now be participated in the light harvesting process like a sensitizer. The photons with the proper energy corresponding to the opened band gap could be absorbed with the AFGs that certainly improved the light harvesting efficiency of the solar cells.

(Fig. 10 is here.)

The calculated LUMO energy of the $\left(\mathrm{TiO}_{2}\right)_{60}$ clusters is $-2.97 \mathrm{eV}(\mathrm{B} 3 \mathrm{LYP} / \mathrm{VDZ})$ [41]. Therefore, the LUMO energies of the AFGs placed upper than the $\mathrm{CB}$ of the $\mathrm{TiO}_{2}$ semiconductor. The electron injection from the excited AFG is thermodynamically facile in compare to the electron transfer from the excited $\mathrm{GO}$ to $\mathrm{TiO}_{2}$ that was resulted in a better photovoltaic performance.

\section{Conclusions}

The amino acid-functionalized GO was incorporated to the $\mathrm{TiO}_{2}$ nanoparticles and used as the photoanodes of the DSSCs. The properties of the AFGs itself and the composite photo-electrode showed a significant difference between the amino acid used for the functionalized GO. The electrical conductivity, electrocatalytic activity and photovoltaic properties of the GO composite directly depend on the structure of the functional amino acids. All the characterization studies showed an improved electrochemical and photovoltaic performance for the aromatic amino acids attached to the GO. The computational approach showed a gap between HOMO and LUMO energies of the functionalized GO that was not observed for the GO. Functionalization of the graphene opens new insights for making new materials with particular properties for using in photo-electrochemical applications. 


\section{Acknowledgement}

The authors acknowledge Iran National Science Foundation, National Elites Foundation, Isfahan University of Technology Research Council (IUT), Isfahan Regional Electrical Company and Centre of Excellency in Sensor and Green Chemistry of IUT for supporting this work.

\section{References}

[1] A. Hagfeldt, G. Boschloo, L. Sun, L. Kloo, H. Pettersson, Dye-sensitized solar cells., Chem. Rev. 110 (2010) 6595-6663.

[2] A. Reynal, E. Palomares, Ruthenium polypyridyl sensitisers in dye solar cells based on mesoporous $\mathrm{TiO}_{2}$, Eur. J. Inorg. Chem. (2011) 4509-4526.

[3] L. Zhang, H. Sun, Z. Xue, B. Liu, Z.-S. Wang, Self-assembled ultrathin titania nanosheets as blocking layers for significantly enhanced photocurrent and photovoltage of dye-sensitized solar cells, J. Mater. Chem. A. 3 (2015) 17042-17049.

[4] G. Sahu, S.W. Gordon, M.A. Tarr, Synthesis and application of core-shell $\mathrm{Au}-\mathrm{TiO}_{2}$ nanowire photoanode materials for dye sensitized solar cells, RSC Adv. 2 (2012) 573.

[5] Y.H. Jang, Y.J. Jang, S.T. Kochuveedu, M. Byun, Z. Lin, D.H. Kim, Plasmonic dye-sensitized solar cells incorporated with $\mathrm{Au}-\mathrm{TiO}_{2}$ nanostructures with tailored configurations., Nanoscale. 6 (2014) 1823-32.

[6] M. Janani, P. Srikrishnarka, S. V. Nair, A.S. Nair, An in-depth review on the role of carbon nanostructures in dye-sensitized solar cells, J. Mater. Chem. A. 3 (2015) 17914-17938.

[7] J.D. Roy-mayhew, I.A. Aksay, Graphene Materials and Their Use in Dye-Sensitized Solar Cells, Chem. Rev. 114 6323-6348.

[8] D. Chen, H. Zhang, Y. Liu, J. Li, Graphene and its derivatives for the development of solar cells, photoelectrochemical, and photocatalytic applications, Energy Environ. Sci. 6 (2013) 1362.

[9] D.W. Chang, H.-J. Choi, A. Filer, J.-B. Baek, Graphene in photovoltaic applications: organic photovoltaic cells (OPVs) and dye-sensitized solar cells (DSSCs), J. Mater. Chem. A. 2 (2014) 
12136.

[10] A.R. bin M. Yusoff, Graphene-based Energy Devices, Wiley-VCH Verlag GmbH, Weinheim, Germany, 2015.

[11] M. Khan, M.N. Tahir, S.F. Adil, H.U. Khan, M.R.H. Siddiqui, A.A. Al-warthan, W. Tremel, Graphene based metal and metal oxide nanocomposites: synthesis, properties and their applications, J. Mater. Chem. A. 3 (2015) 18753-18808.

[12] V. Georgakilas, M. Otyepka, A.B. Bourlinos, V. Chandra, N. Kim, K.C. Kemp, P. Hobza, R. Zboril, K.S. Kim, Functionalization of graphene: Covalent and non-covalent approaches, derivatives and applications, 2012.

[13] H. Chang, H. Wu, Graphene-based nanocomposites: preparation, functionalization, and energy and environmental applications, Energy Environ. Sci. 6 (2013) 3483.

[14] C.K. Chua, M. Pumera, Chemical reduction of graphene oxide: a synthetic chemistry viewpoint., Chem. Soc. Rev. 43 (2014) 291-312.

[15] W. Gao, L.B. Alemany, L. Ci, P.M. Ajayan, New insights into the structure and reduction of graphite oxide., Nat. Chem. 1 (2009) 403-408.

[16] D. Chen, L. Li, L. Guo, An environment-friendly preparation of reduced graphene oxide nanosheets via amino acid., Nanotechnology. 22 (2011) 325601.

[17] D.N.H. Tran, S. Kabiri, D. Losic, A green approach for the reduction of graphene oxide nanosheets using non-aromatic amino acids, Carbon N. Y. 76 (2014) 193-202.

[18] N. Dragneva, W.B. Floriano, D. Stauffer, R.C. Mawhinney, G. Fanchini, O. Rubel, Favorable adsorption of capped amino acids on graphene substrate driven by desolvation effect, J. Chem. Phys. 139 (2013) 174711.

[19] H. Vovusha, S. Sanyal, B. Sanyal, Interaction of nucleobases and aromatic amino acids with graphene oxide and graphene flakes, J. Phys. Chem. Lett. 4 (2013) 3710-3718.

[20] C. Cazorla, Ab initio study of the binding of collagen amino acids to graphene and A-doped (A=H, Ca) graphene, Thin Solid Films. 518 (2010) 6951-6961. 
[21] S. Mallakpour, A. Abdolmaleki, S. Borandeh, Covalently functionalized graphene sheets with biocompatible natural amino acids, Appl. Surf. Sci. 307 (2014) 533-542.

[22] B. Rezaei, M. Taki, A.A. Ensafi, Modulated electrical field as a new pulse method to make $\mathrm{TiO}_{2}$ film for high- performance photo-electrochemical cells and modeling of the deposition process, J. Solid State Electrochem. (2016). doi:10.1007/s10008-016-3363-8.

[23] F. Neese, The ORCA program system, Wiley Interdiscip. Rev. Comput. Mol. Sci. 2 (2012) 73.

[24] A.R. Allouche, Gabedit - A graphical user interface for computational chemistry softwares, J. Comput. Chem. 32 (2011) 174-182.

[25] T. Lu, F. Chen, Multiwfn: A multifunctional wavefunction analyzer, J. Comput. Chem. 33 (2012) $580-592$.

[26] D.A.C. Brownson, C.E. Banks, The handbook of Graphene Electrochemistry, 2014.

[27] R. Holze, Understanding voltammetry: Simulation of electrode processes, J. Solid State Electrochem. 20 (2016) 305-306.

[28] Y. Shao, J. Wang, M. Engelhard, C. Wang, Y. Lin, Facile and controllable electrochemical reduction of graphene oxide and its applications, J. Mater. Chem. 20 (2010) 743.

[29] S. Gilje, R.B. Kaner, G.G. Wallace, D.A.N. Li, M.B. Mu, M.B. Muller, S. Gilje, R.B. Kaner, G.G. Wallace, Processable aqueous dispersions of graphene nanosheets, Nat. Nanotechnol. 3 (2008) $101-105$.

[30] J.-H.H. Yum, S.-S.S. Kim, D.-Y.Y. Kim, Y.-E.E. Sung, Electrophoretically deposited $\mathrm{TiO}_{2}$ photoelectrodes for use in flexible dye-sensitized solar cells, J. Photochem. Photobiol. A Chem. 173 (2005) 1-6.

[31] S.S. Mali, C. a. Betty, P.N. Bhosale, P.S. Patil, Synthesis, Characterization of Hydrothermally Grown MWCNT-TiO 2 Photoelectrodes and Their Visible Light Absorption Properties, ECS J. Solid State Sci. Technol. 1 (2012) M15-M23.

[32] Y. Zhu, X. Meng, H. Cui, S. Jia, J. Dong, J. Zheng, J. Zhao, Z. Wang, L. Li, L. Zhang, Z. Zhu, Graphene frameworks promoted electron transport in quantum dot-sensitized solar cells, ACS 
Appl. Mater. Interfaces. 6 (2014) 13833-13840.

[33] F. Cao, G. Oskam, P. Searson, Electrical and optical properties of porous nanocrystalline $\mathrm{TiO}_{2}$ films, J. Phys. Chem. 99 (1995) 11974- 11980.

[34] M.K. Nazeeruddin, R. Splivallo, P. Liska, P. Comte, M. Grätzel, A swift dye uptake procedure for dye sensitized solar cells., Chem. Commun. (Camb). (2003) 1456-1457.

[35] R. Kern, R. Sastrawan, J. Ferber, R. Stangl, J. Luther, Modeling and interpretation of electrical impedance spectra of dye solar cells operated under open-circuit conditions, Electrochim. Acta. 47 (2002) 4213-4225.

[36] Q. Wang, J.-E. Moser, M. Grätzel, Electrochemical impedance spectroscopic analysis of dyesensitized solar cells., J. Phys. Chem. B. 109 (2005) 14945-53.

[37] M. Adachi, M. Sakamoto, J. Jiu, Y. Ogata, S. Isoda, Determination of parameters of electron transport in dye-sensitized solar cells using electrochemical impedance spectroscopy., J. Phys. Chem. B. 110 (2006) 13872-80.

[38] L. Dloczik, O. Ileperuma, I. Lauermann, L.M. Peter, E.A. Ponomarev, G. Redmond, N.J. Shaw, I. Uhlendorf, Dynamic Response of Dye-Sensitized Nanocrystalline Solar Cells: Characterization by Intensity-Modulated Photocurrent Spectroscopy, J. Phys. Chem. B. 101 (1997) 10281-10289.

[39] J. Krüger, R. Plass, M. Grätzel, P.J. Cameron, L.M. Peter, J. Kruger, R. Plass, M. Gratzel, P.J. Cameron, L.M. Peter, Charge transport and back reaction in solid-state dye-sensitized solar cells: A study using intensity-modulated photovoltage and photocurrent spectroscopy, J. Phys. Chem. B. 107 (2003) 7536-7539.

[40] S.P. Lim, A. Pandikumar, N.M. Huang, H.N. Lim, Enhanced photovoltaic performance of silver@ titania plasmonic photoanode in dye-sensitized solar cells, RSC Adv. 4 (2014) 3811138118.

[41] P.S. Kumar, K. Vasudevan, A. Prakasam, M. Geetha, P.M. Anbarasan, Quantum chemistry calculations of 3-Phenoxyphthalonitrile dye sensitizer for solar cells, Spectrochim. Acta - Part A Mol. Biomol. Spectrosc. 77 (2010) 45-50. 


\section{Figure Captions}

Fig. 1: CVs recorded with GO and AFGs immobilized on GC as the working electrode in solution of $\mathrm{Fe}(\mathrm{CN})_{6}{ }^{4-}$ with the scan rate of $50 \mathrm{mV} \mathrm{s}^{-1}$ (a). EIS spectra obtained in the frequency range of $10^{-1}$ to $10^{5} \mathrm{~Hz}$ in the same Fe (II) solution (b). Electrochemical reduction of the AFGs that was performed during $\mathrm{CV}$ in buffer solution with $\mathrm{pH}$ of 11 (c)

Fig. 2: FTIR spectra of the AFGs incorporated $\mathrm{TiO}_{2}$.

Fig. 3: SEM images of the $\mathrm{AFGs}-\mathrm{TiO}_{2}$ films obtained in backscatter mode. The incorporated AFGs were GO (a), GO-Alanine (b), GO-Isoleucine (c), GO-Leucine (d), GO-Methionine (e), GO-Phenylalanine (f), GO-Tyrosine (g), GO-Valine (h) and pure $\mathrm{TiO}_{2}$ (i). The white dots are carbonaceous material embedded in the film and the white line is FTO layer of the substrate.

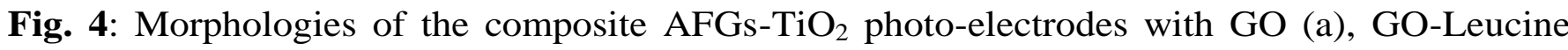
(b), GO-Valine (c) and GO-Alanine (d). The concentration of the incorporated AFGs was $0.25 \%$.

Fig. 5: Absorption spectrum of the dye-loaded composite photo-electrodes. The recorded data were corrected by omitting the absorption of the blank composite $\mathrm{TiO}_{2}$ layers.

Fig. 6: Photovoltaic performance of the fabricated DSSCs with the photoanodes having the AFGs additives under illumination of the simulated AM 1.5 sunlight $\left(100 \mathrm{~mW} \mathrm{~cm}^{-2}\right)$.

Fig. 7: External light harvesting efficiencies of the DSSCs fabricated with the photoanodes having incorporated AFGs obtained in different wavelength.

Fig. 8: The transient photo-voltage decays (a), and the electron lifetimes in various open circuit voltages of the DSSCs (b) resulted from the OCVD measurement. Nyquist plots obtained from the EIS studies of the illuminating DSSCs in the frequency range of $10^{-2}$ to $10^{5} \mathrm{~Hz}$ and the electrical circuit model used for fitting the EIS data (c) and the IMPS response of the DSSCs illuminated with a blue light LED $(455 \mathrm{~nm})$ modulated in the frequency range of $10^{-2}$ to $20 \mathrm{~Hz}$ (d). 
Fig. 9: The geometry-optimized structures of the GO and AFGs resulted from the DFT calculations (a) and mesh-surface illustrations of the aromatic amino acid functionalized GO (b).

Fig. 10: The DOS graphs resulted from estimated molecular orbital energies of the AFG sheets (a) and the energy of opened band gap of the AFGs in compare to the Fermi level of the GO and the LUMO energy of $\mathrm{TiO}_{2}(\mathrm{~b})$.

\section{Table Captions}

Table 1: The results of electrochemical studies on the GO and AFGs.

Table 2: Zeta potential of the AFG particles suspended in alkaline aqueous solvent with the concentration of $1 \mathrm{~g} \mathrm{~L}^{-1}$.

Table 3: The photovoltaic parameters of the assembled solar cells with the AFGs incorporated $\mathrm{TiO}_{2}$ photo-electrodes and the flat band potential resulted from the Mott-Schottky analysis.

Table 4: Electron transport times resulted from the IMPS and electron lifetimes and photoelectron injection resistances resulted from the EIS studies. 
Figures

Fig. 1
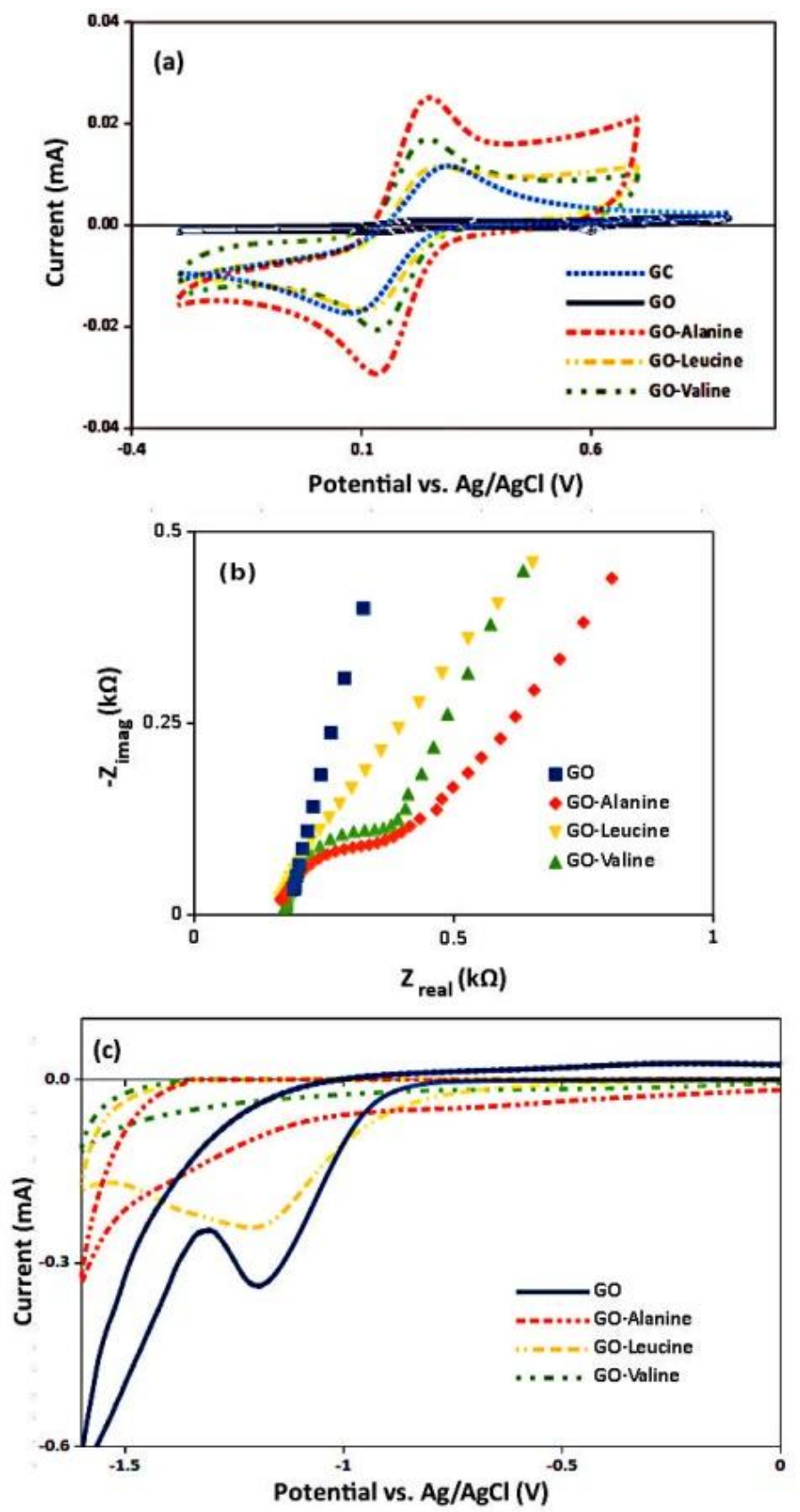
Fig. 2

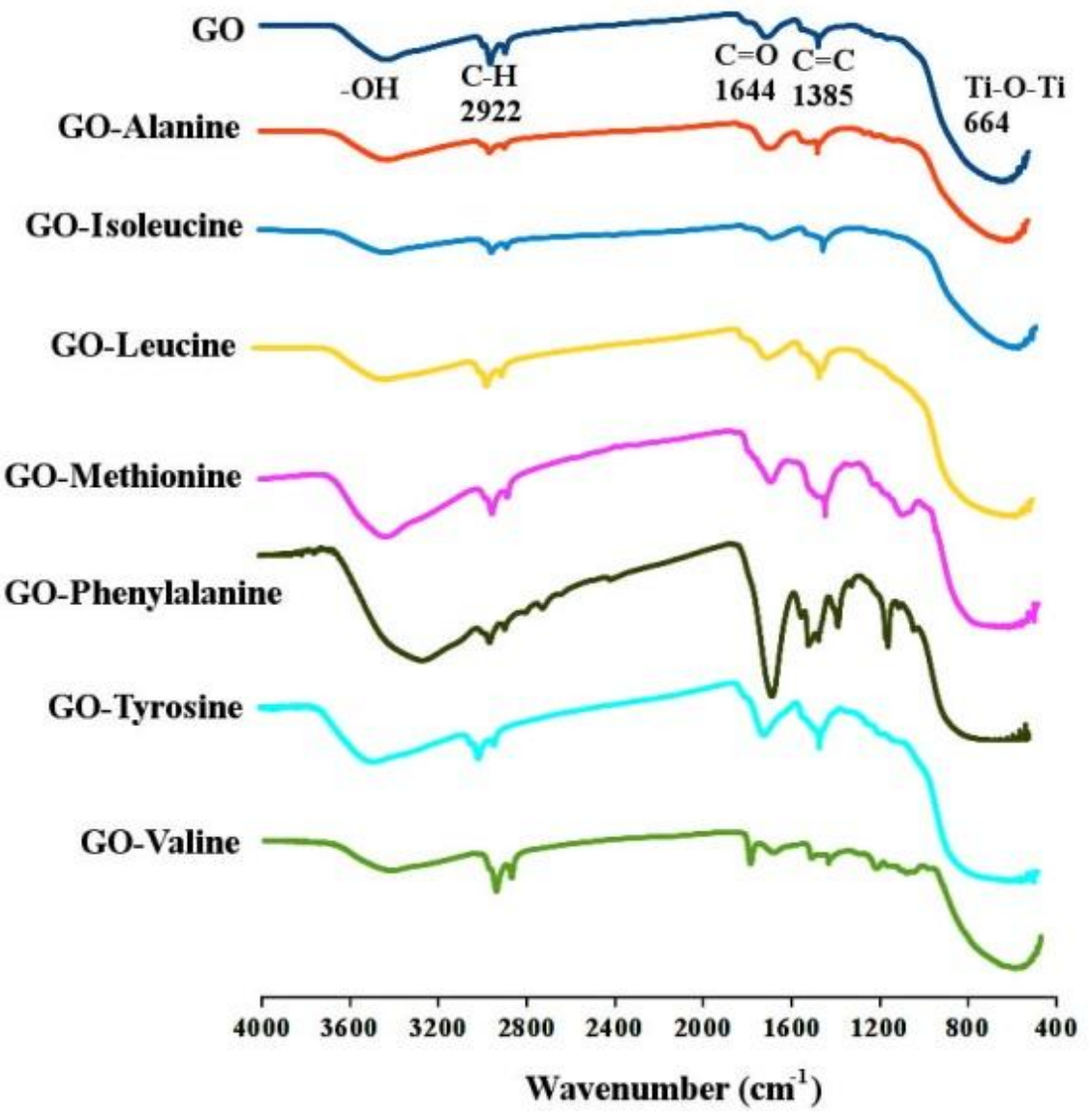


Fig. 3
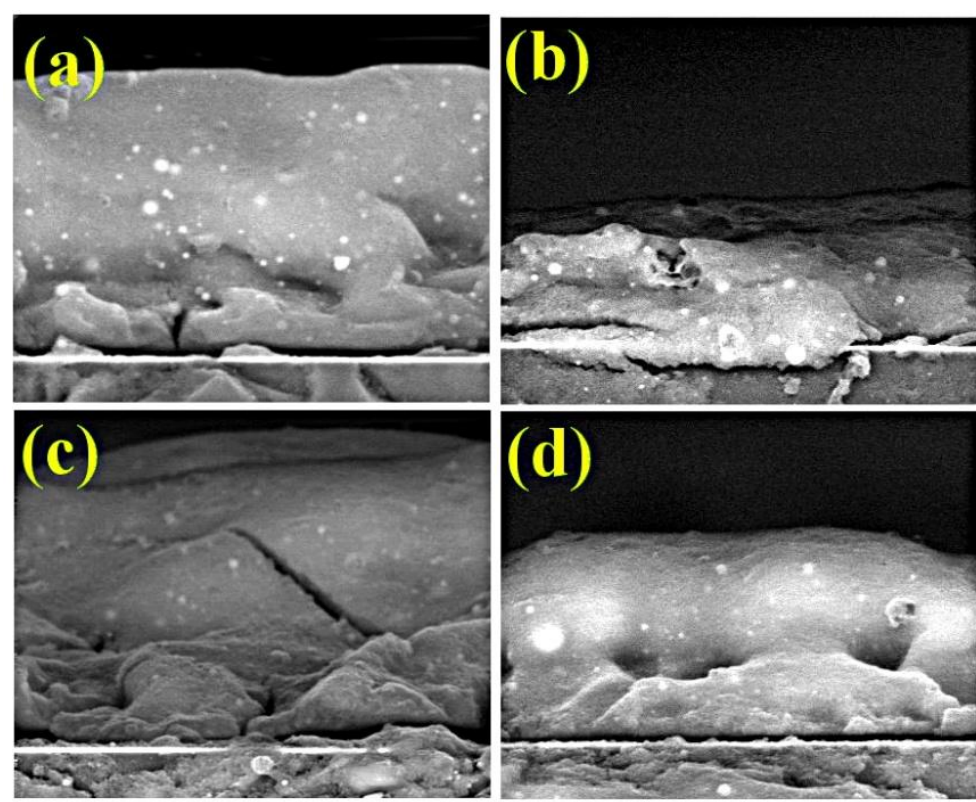

(d)
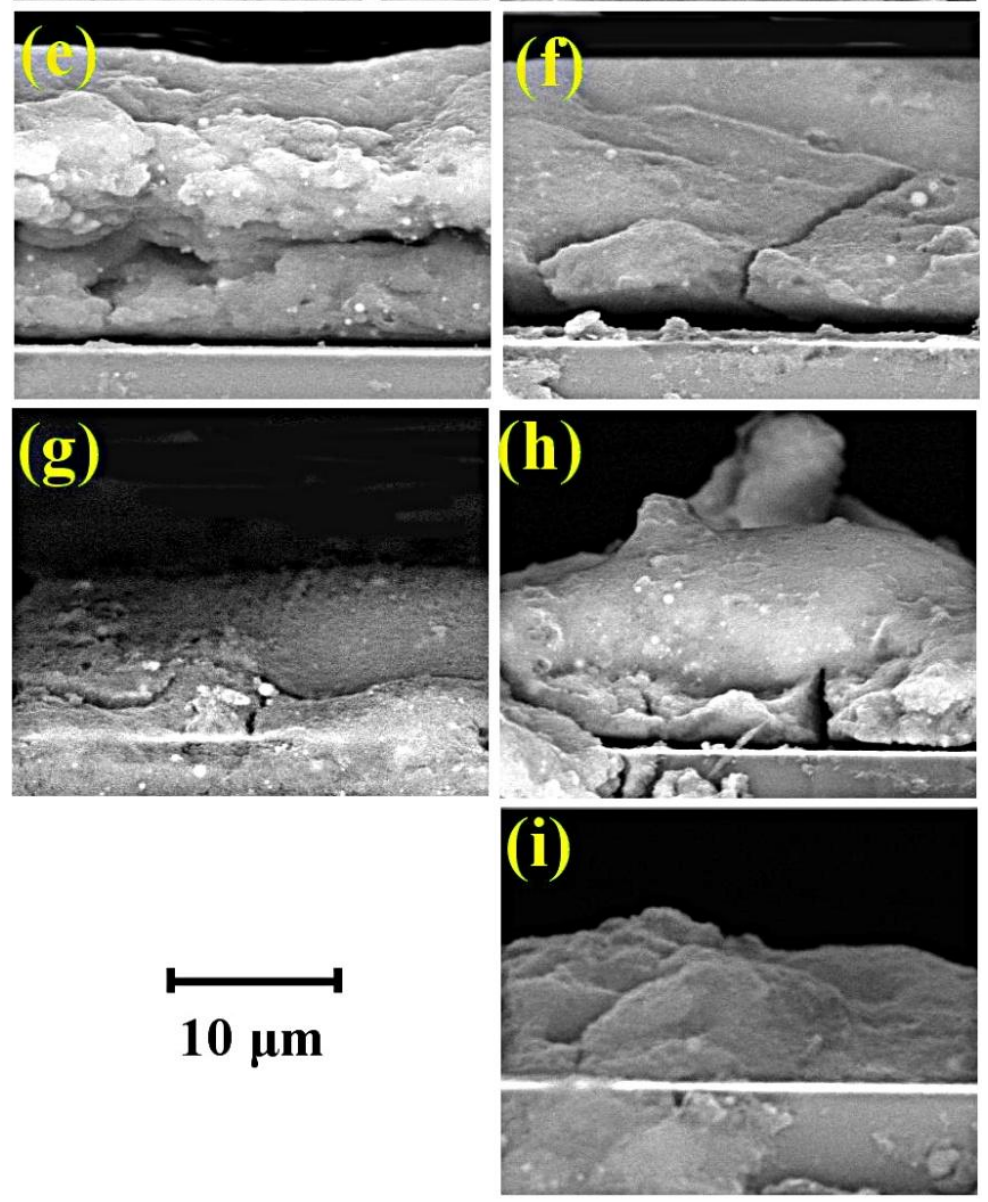
Fig. 4

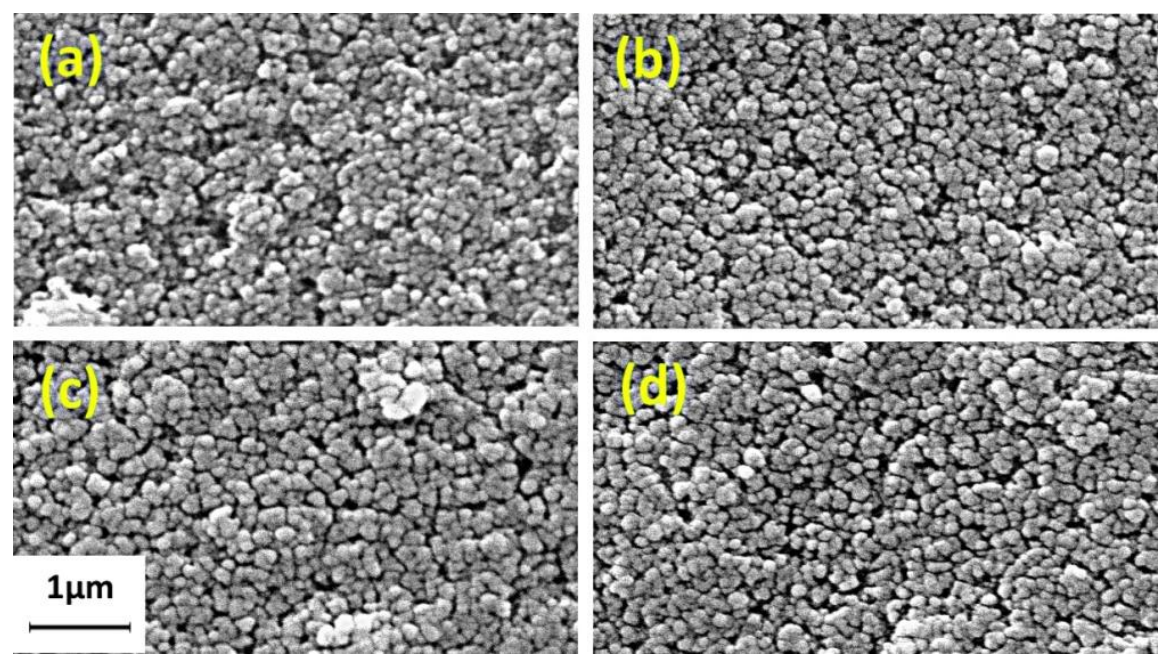

Fig. 5

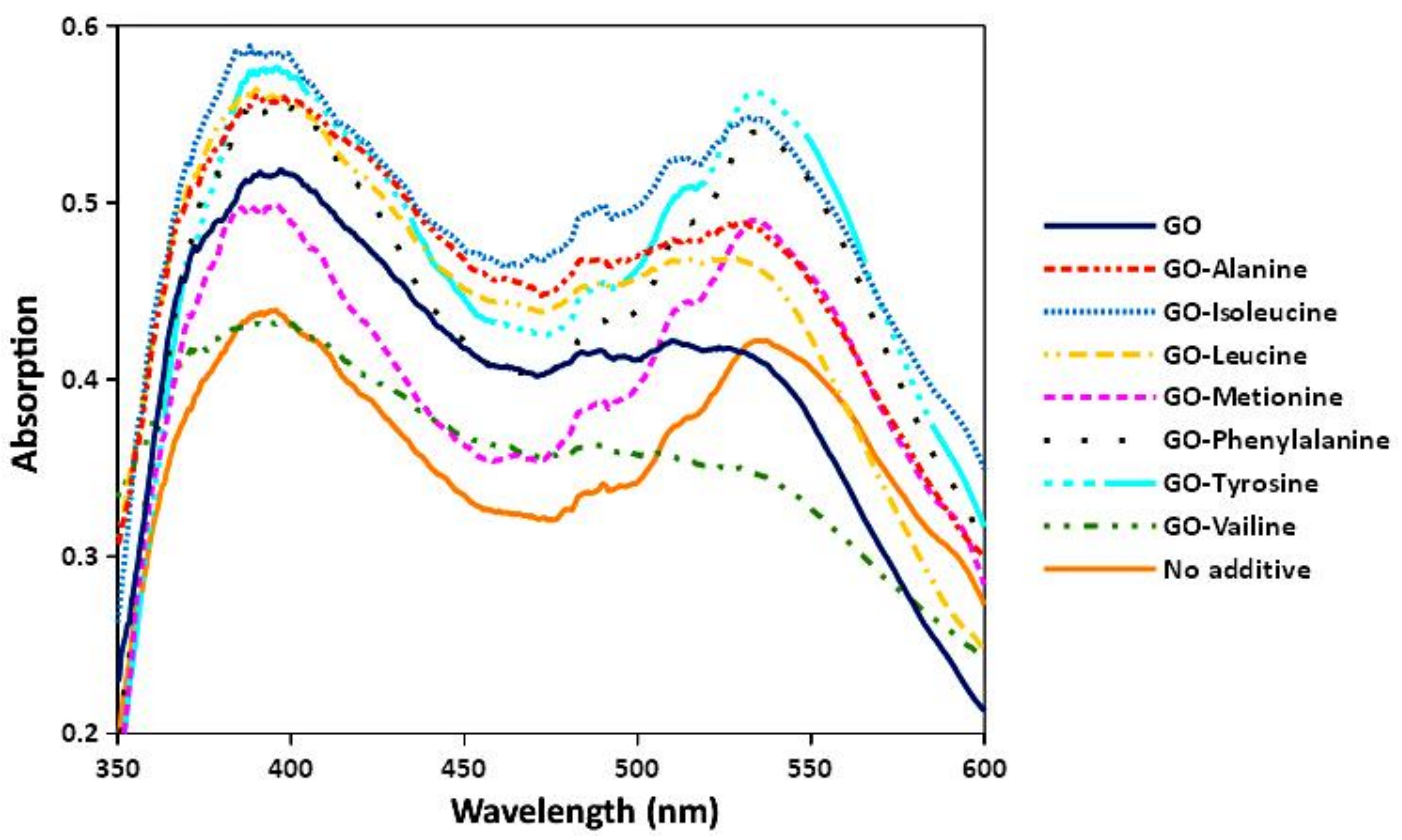


Fig. 6

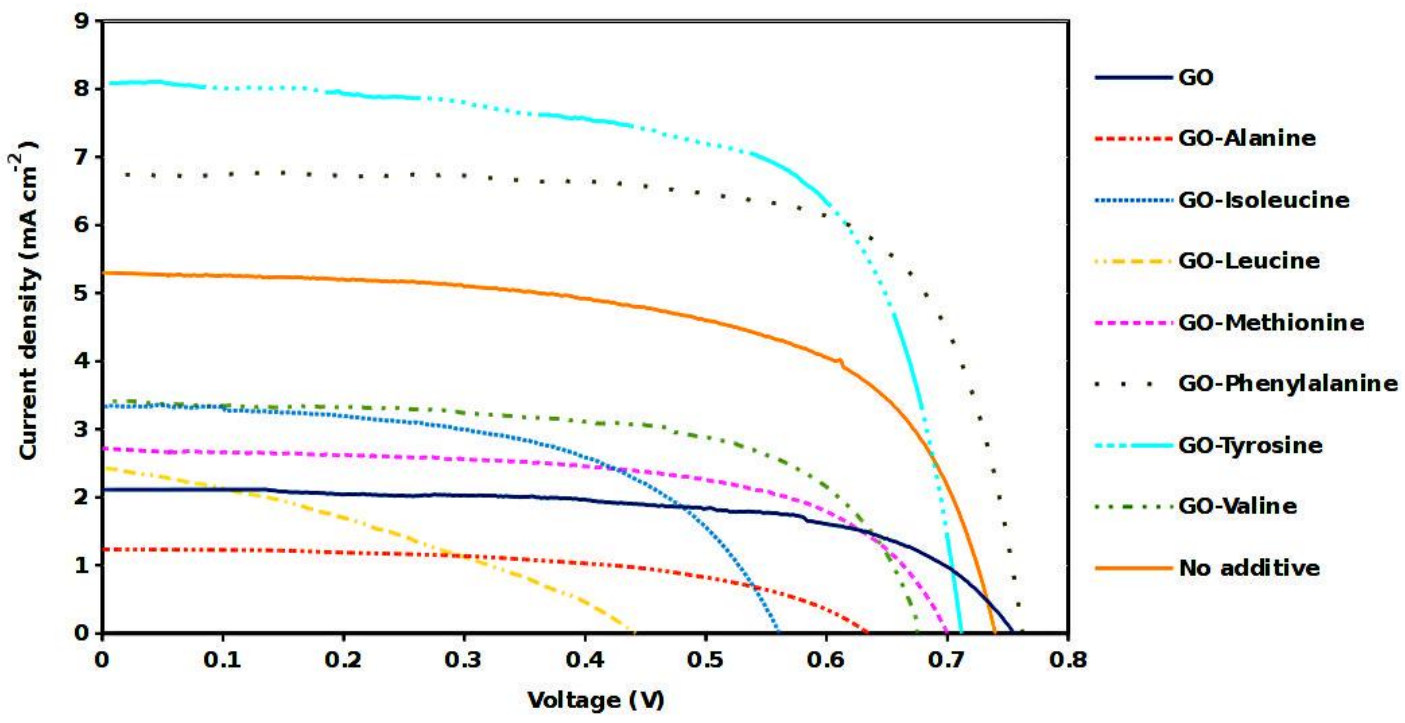

Fig. 7
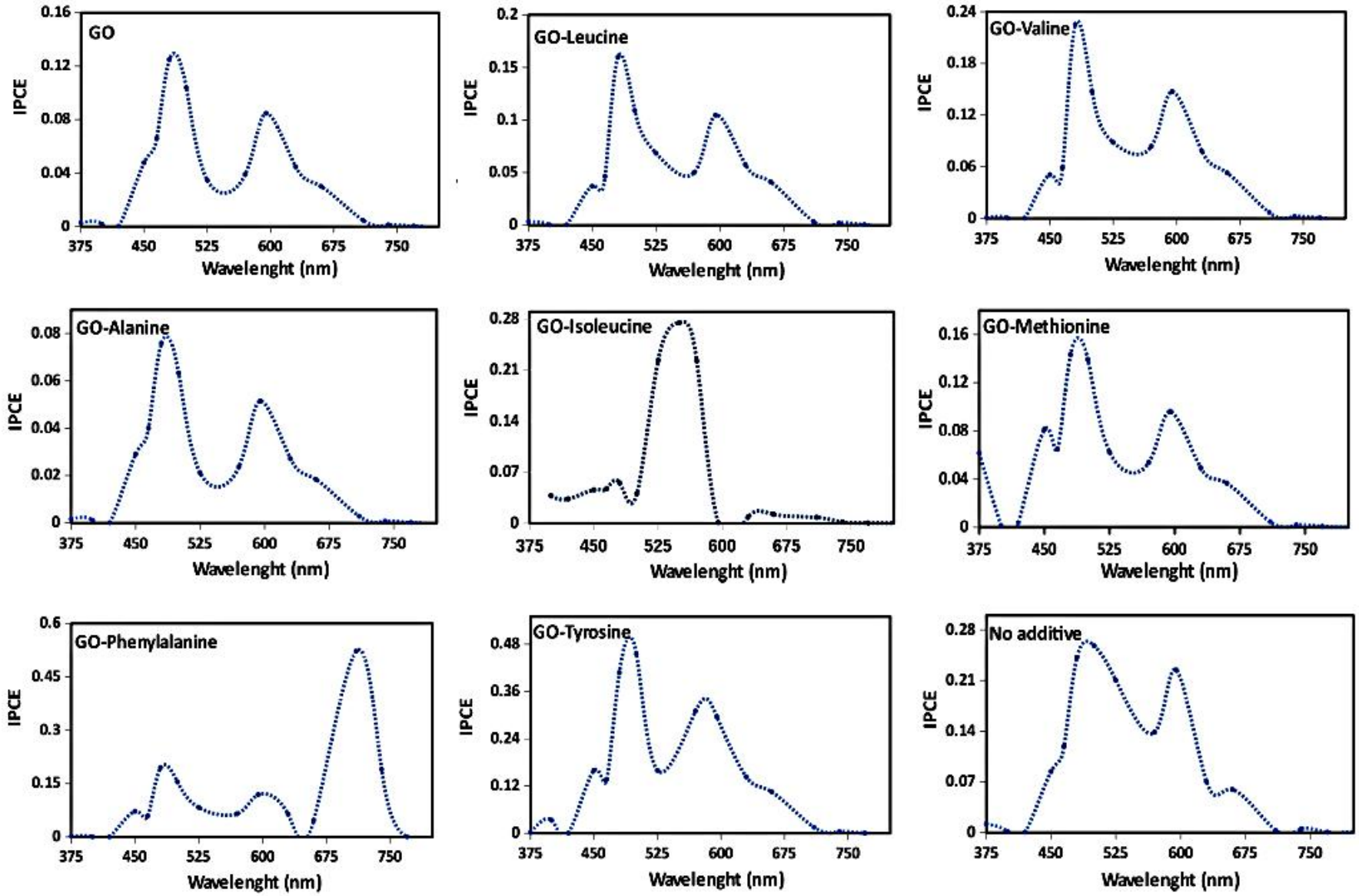
Fig. 8
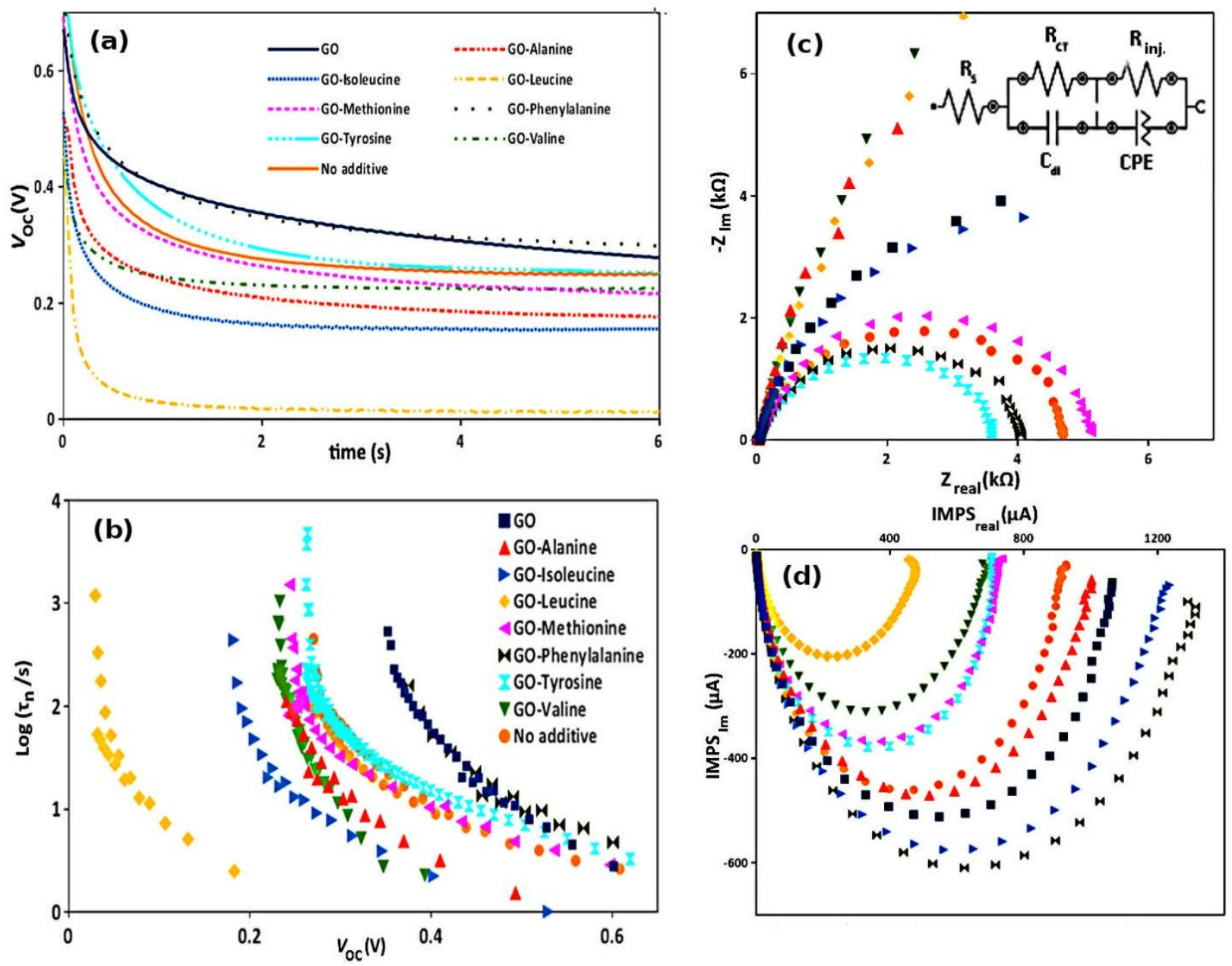
Fig. 9

(a)

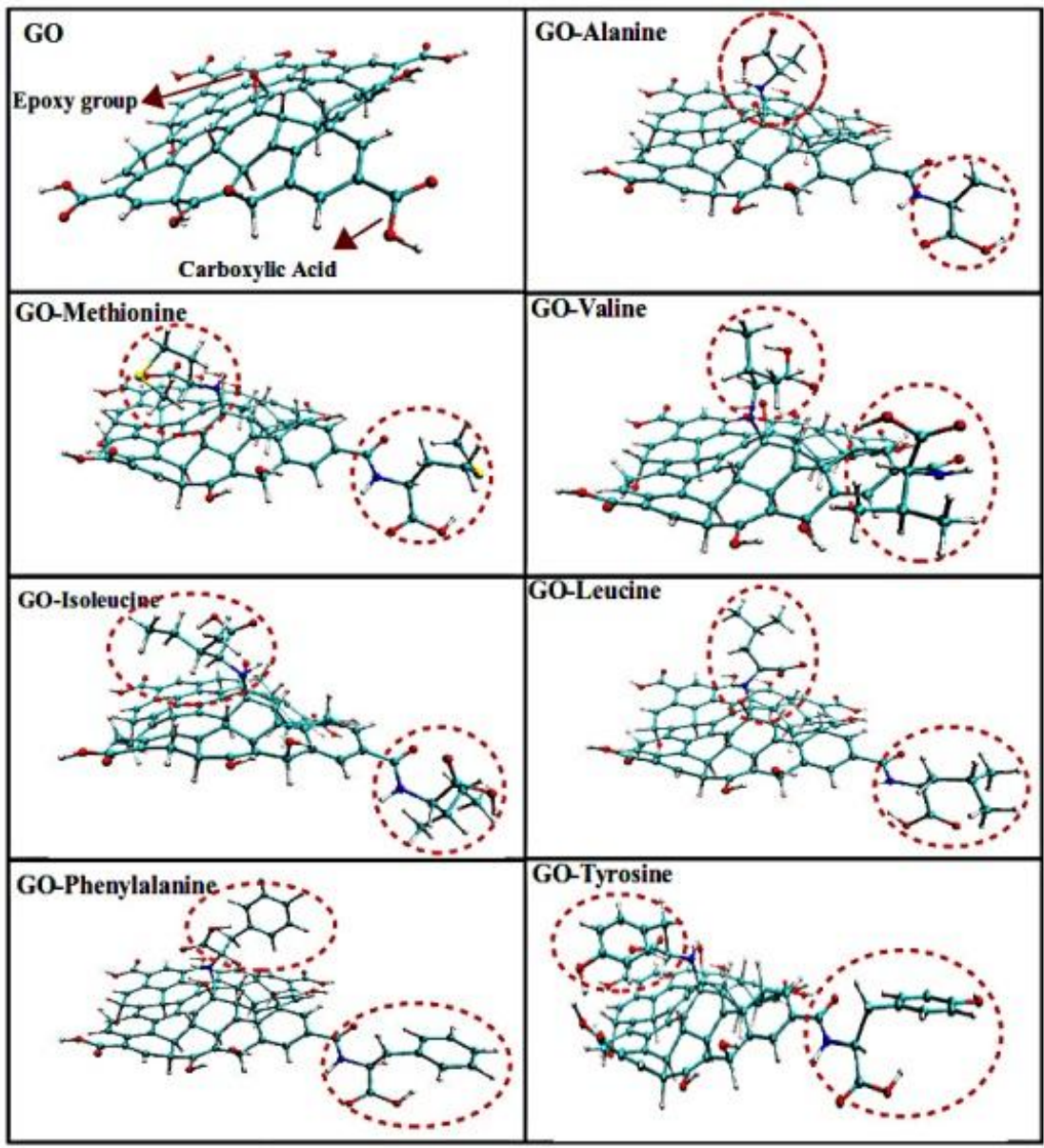

(b)

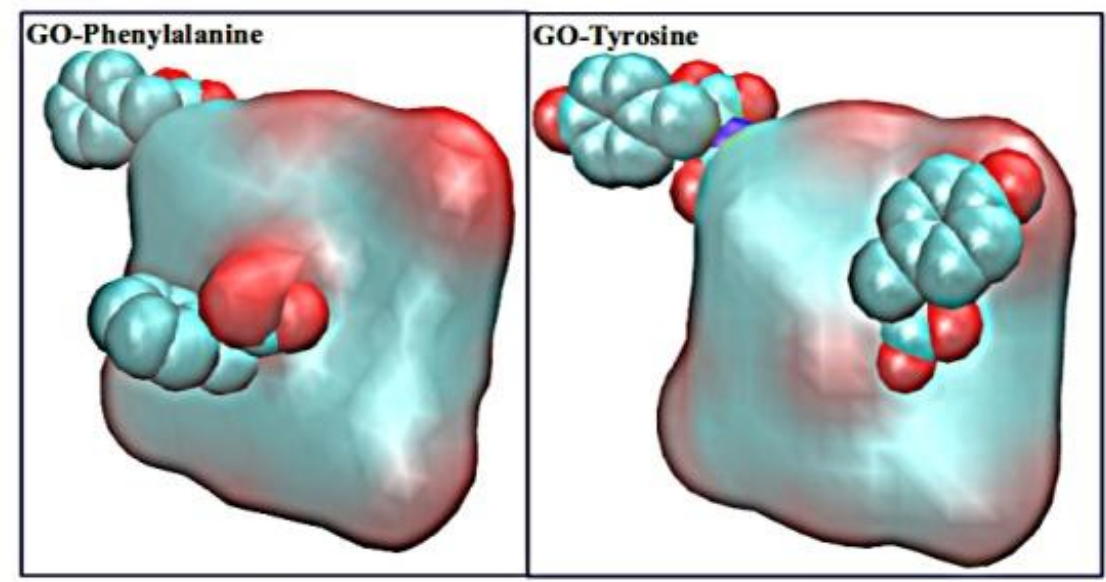


Fig. 10
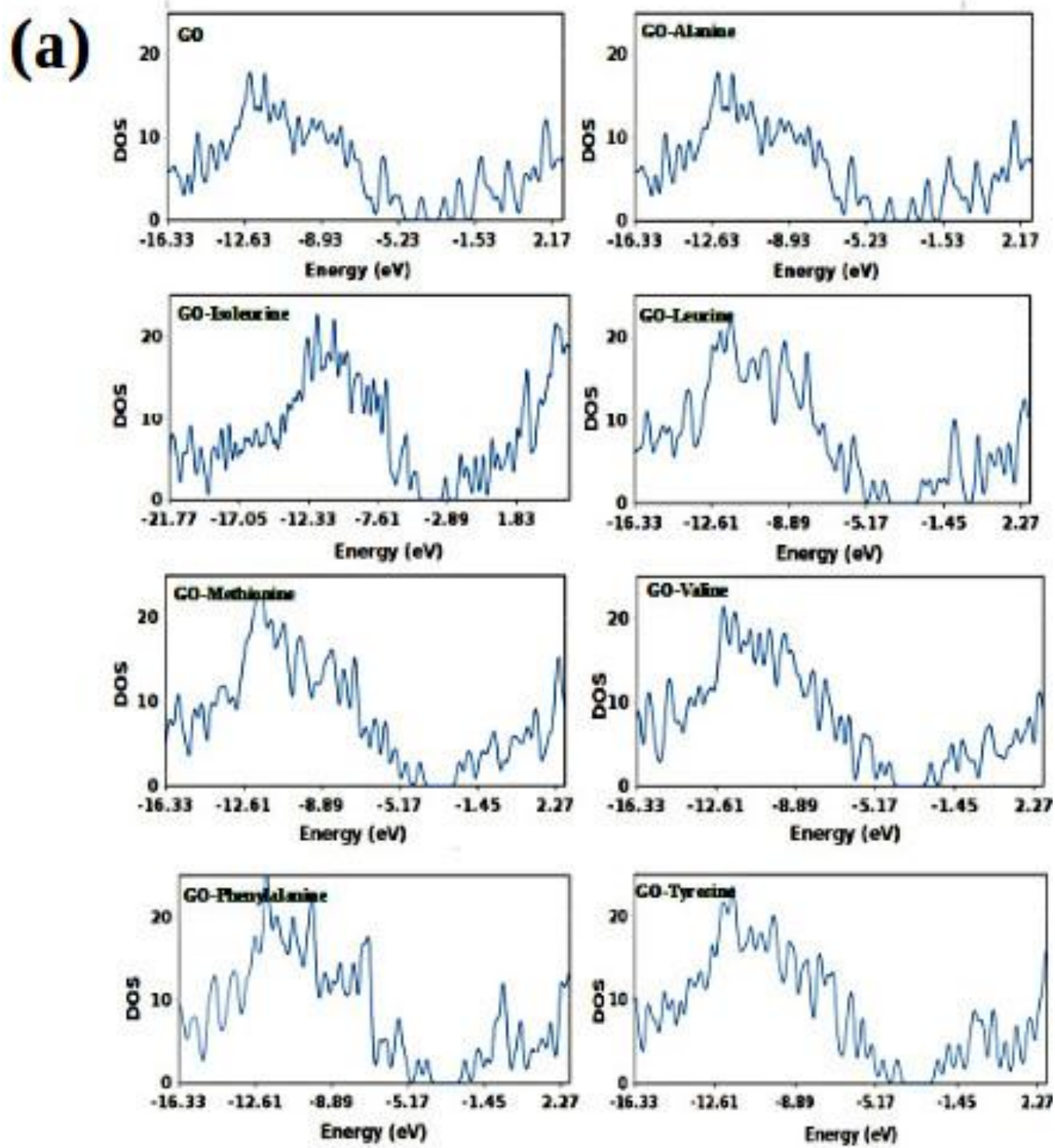

(b)

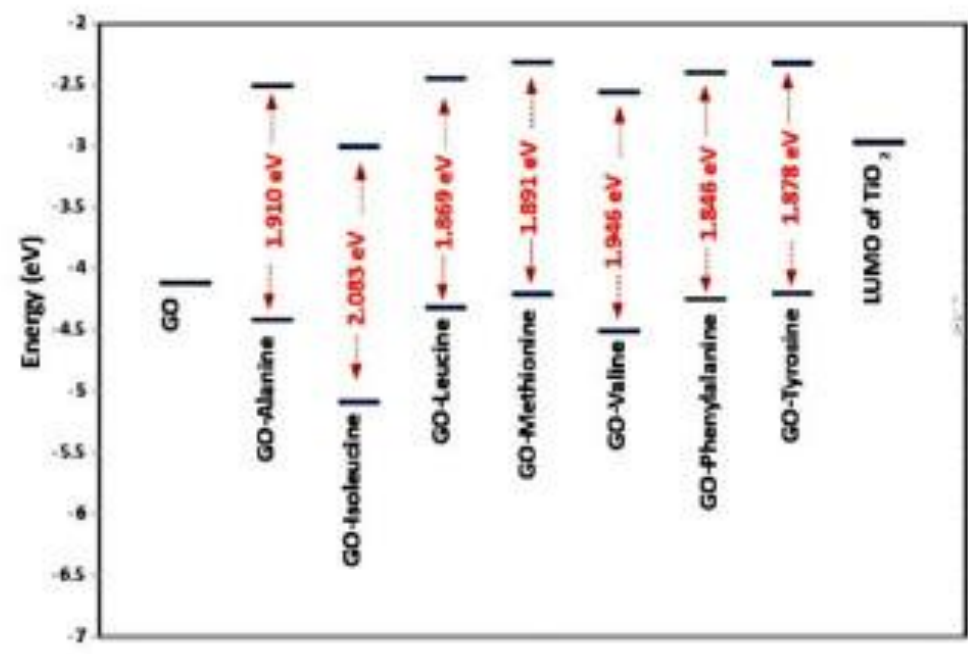




\section{Tables}

Table 1

\begin{tabular}{cccc} 
GO-amino acids & $i_{\mathrm{pa}}(\mu \mathrm{A})$ & $R_{\mathrm{ct}}(\Omega)$ & $i_{\text {red }}(\mu \mathrm{A})$ \\
\hline none & 0.66 & 4735 & 146 \\
Alanine & 20.83 & 240 & $\mathrm{NA}^{*}$ \\
Isoleucine & 2.22 & 3665 & 320 \\
Leucine & 11.09 & 5775 & 138 \\
Methionine & 18.24 & 697 & 1 \\
Phenylalanine & 15.72 & 2940 & 18 \\
Tyrosine & 18.72 & 1645 & NA \\
Valine & 15.71 & 104 & NA \\
\hline
\end{tabular}

* No reduction peak was observed.

\section{Table 2}

GO-

amino none Alanine Isoleucine Leucine Methionine Phenylalanine Tyrosine Valine acids

\begin{tabular}{|c|c|c|c|c|c|c|c|c|}
\hline \multicolumn{9}{|l|}{ Zeta } \\
\hline potential & -5.12 & -21.4 & -24.3 & -6.18 & -6.23 & -3.19 & -3.28 & -22.5 \\
\hline
\end{tabular}


Table 3

\begin{tabular}{cccccc}
$\begin{array}{c}\text { GO-amino } \\
\text { acids }\end{array}$ & $V_{\mathrm{OC}}(\mathrm{V})$ & $J_{\mathrm{SC}}\left(\mathrm{mA} \mathrm{cm}^{-2}\right)$ & $\mathrm{FF}(\%)$ & $\eta(\%)$ & $\begin{array}{c}E_{\mathrm{fb}} \\
(\mathrm{V} \text { vs. NHE })\end{array}$ \\
\hline None & $0.771 \pm 0.001$ & $2.112 \pm 0.066$ & $61.0 \pm 1.6$ & $0.99 \pm 0.04$ & -0.624 \\
Alanine & $0.664 \pm 0.003$ & $1.234 \pm 0.060$ & $50.4 \pm 0.5$ & $0.41 \pm 0.01$ & -1.262 \\
Isoleucine & $0.583 \pm 0.003$ & $3.146 \pm 0.012$ & $57.1 \pm 0.5$ & $1.05 \pm 0.01$ & -1.094 \\
Leucine & $0.456 \pm 0.011$ & $2.509 \pm 0.060$ & $36.4 \pm 2.3$ & $0.42 \pm 0.02$ & -5.015 \\
Methionine & $0.699 \pm 0.011$ & $2.718 \pm 0.009$ & $67.0 \pm 1.1$ & $1.27 \pm 0.06$ & -1.470 \\
Phenylalanine & $0.762 \pm 0.009$ & $6.638 \pm 0.008$ & $65.8 \pm 1.0$ & $3.33 \pm 0.07$ & -0.670 \\
Tyrosine & $0.694 \pm 0.003$ & $8.190 \pm 0.007$ & $72.6 \pm 0.3$ & $4.13 \pm 0.02$ & -1.459 \\
Valine & $0.662 \pm 0.004$ & $3.461 \pm 0.071$ & $48.1 \pm 4.1$ & $1.10 \pm 0.01$ & -0.788 \\
No additive & $0.745 \pm 0.003$ & $5.351 \pm 0.004$ & $58.5 \pm 0.3$ & $2.33 \pm 0.01$ & -0.968 \\
\hline
\end{tabular}

Table 4

\begin{tabular}{cccc} 
GO-Amino acids & $\tau_{\mathrm{n}}(\mathrm{s})$ & $R_{\text {inj. }}(\mathrm{k} \Omega)$ & $\tau_{\mathrm{d}}(\mathrm{s})$ \\
\hline None & 1.384 & 8.51 & 0.835 \\
Alanine & 1.382 & 17.3 & 0.835 \\
Isoleucine & 0.786 & 6.05 & 0.715 \\
Leucine & 1.047 & 14.8 & 0.524 \\
Methionine & 1.043 & 3.69 & 0.449 \\
Phenylalanine & 0.786 & 4.03 & 0.975 \\
Tyrosine & 1.043 & 2.89 & 0.385 \\
Valine & 1.384 & 22.7 & 0.524 \\
No additive & 0.593 & 4.63 & 0.449 \\
\hline
\end{tabular}




\section{Graphical Abstract}

\section{Beneficial effects of amino acid-functionalized graphene nanosheets incorporated in the}

photoanode material of dye-sensitized solar cells: A practical and theoretical study

Mahmood Taki, Behzad Rezaei ${ }^{2}$ Najmeh Fani, Sedigheh Borandeh, Amir Abdolmaleki, Ali A. Ensafi

Department of Chemistry, Isfahan University of Technology, Isfahan 84156-83111, IR Iran

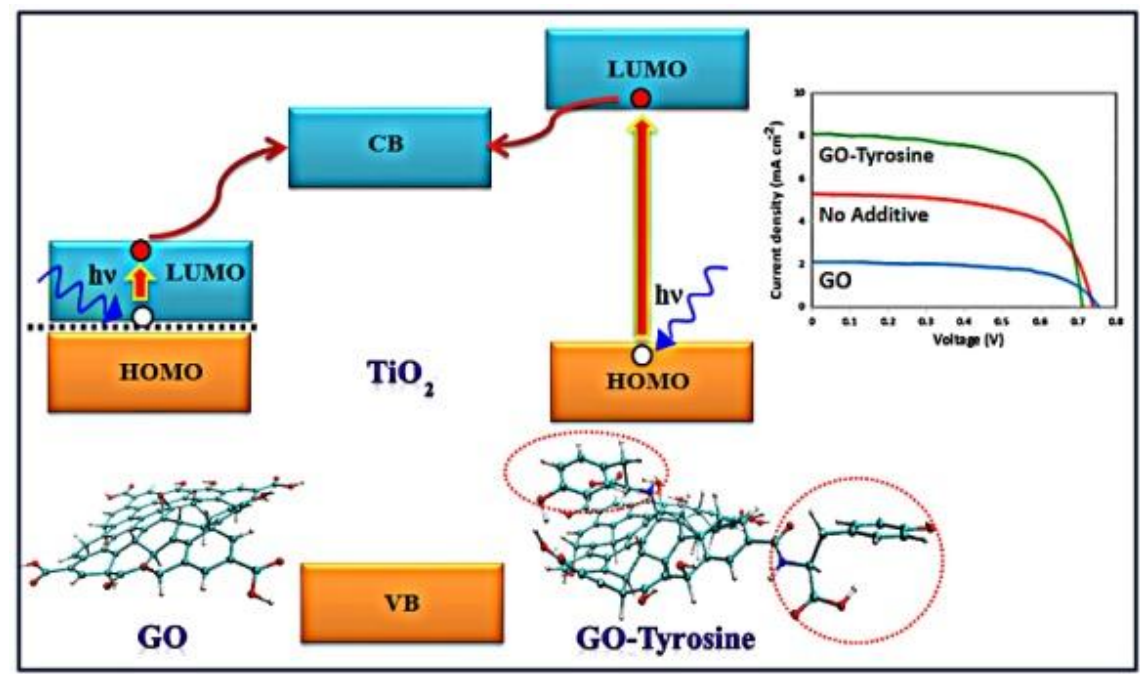

${ }^{2}$ Corresponding Author. Tel.: +983133913268; fax: +98 3133912350 .

E-mail address: rezaei@cc.iut.ac.ir, rezaeimeister@gmail.com. 